\title{
PORTFOLIO
}

\section{Urban Coding in Logan. Teaching urban design with the support of local government} Mirko Guaralda

Queensland University of Technology, Australia Faculty of Creative Industries, School of Design

m.guaralda@qut.edu.au

Since 2015 Logan City Council (LCC), a major urban area south of Brisbane in Queensland, Australia, has hosted students from the Bachelor of Design (Architectural Studies) at the Queensland University of Technology (QUT) for an intensive two-day urban design charrette. The charrette is delivered as coursework and assessment for an architecture unit on urban morphology and urban dynamics; the format of this learning experience allows students to directly interact with Council personnel and to gain an in-depth understanding of the urban issues they are asked to solve. Over the years, LCC has offered engaging and challenging briefs to the students.
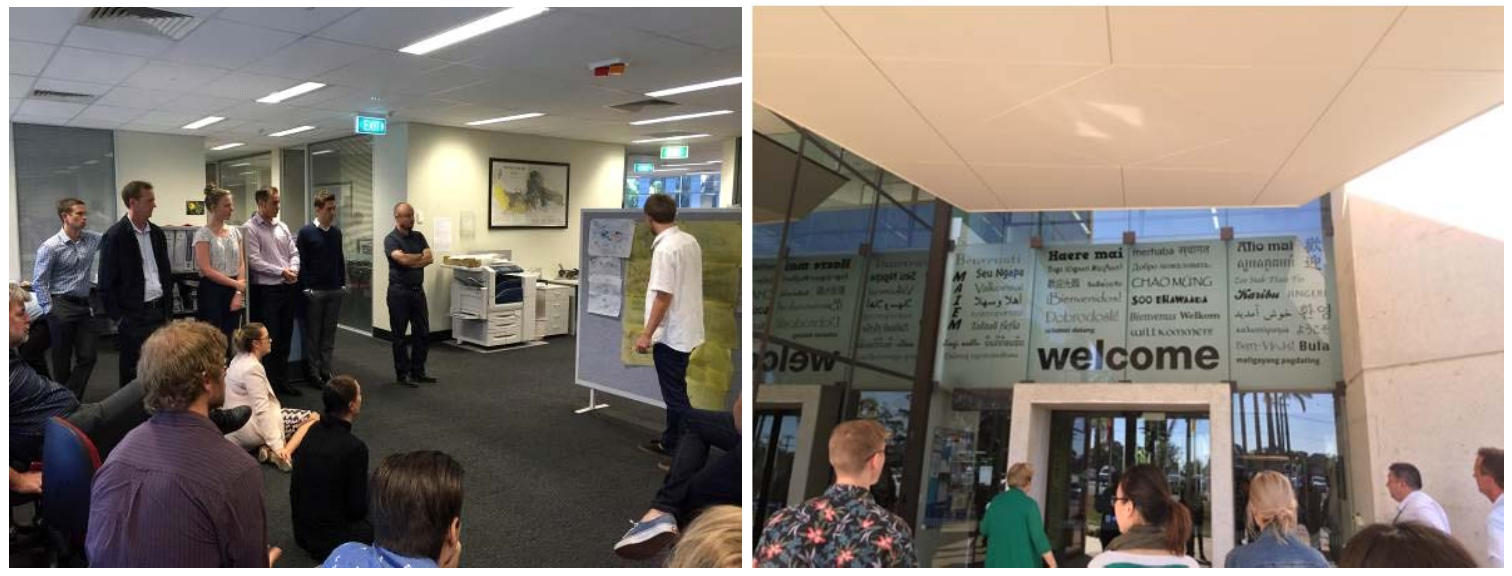

Figure I (left). QUT students presenting their ideas to LCC staff in 2015.

Figure 2 (right). Logan City Council Chambers entrance with welcome messages in the different languages spoken within the urban area

In 2015 the theme was the densification of Wembley Road, the main commercial spine of Logan Central currently characterized by the fragmented forms of big boxes and large carparks. In 2016 students were challenged with the design of a new masterplan for Logan Central Civic and Community Precinct $s$ with the aim of creating a new civic and urban centre. In 2017 the focus was Springwood and the brief sought the creation of a new CBD alongside the $\mathrm{MI}$, the main motorway between Brisbane and the Gold Coast and southern states. In each instance, LCC has provided both the facilities where the workshop was hosted, and engaged several stakeholders to speak to the students. This mix of perspectives presented diverse issues and questions from the local area.

The approach suggested to students was initially developed in collaboration with Prof. Peter Richards and is based on the use of collage as the main tool to understand spaces and 
relationships. Architecture students often find designing at urban scale challenging specifically designing public spaces. Asking students to source information and images of public spaces they regard as successful to use in creating their own proposition has proven to be an effective way of achieving innovative design propositions in a short span of time.

The six projects presented in this paper, have all been developed over just two days, plus some extra time to polish the graphics and finalise the presentation boards, they illustrate a summary of the work by David Pauli in 2015; Ethan Fitzpatrick, Izak Hollins and Alexandra Illuk in 2016; Jessica Fenton and Kristofer Rhodes-Estes in 2017. The workshops were organised by Unit Coordinator/Senior Lecturer Dr Mirko Guaralda with the valued support of sessional academics Linda Carroli and Dr Kirralie Houghton. This interdisciplinary facilitation team was highly experienced in working with local government across diverse portfolios. The first half day of the workshop is dedicated to presentations by stakeholders, Council staff and site visit. The second half of the first day and the majority of the second day are devoted to brainstorming ideas and developing the collage, using samples from other cities to quickly suggest possible networks of public spaces and urban landscapes. The workshop is closed with presentations of the students' ideas to Council and general feedback is provided. After the workshop students have one week to polish their masterplan and finalise their propositions before they are exhibited.
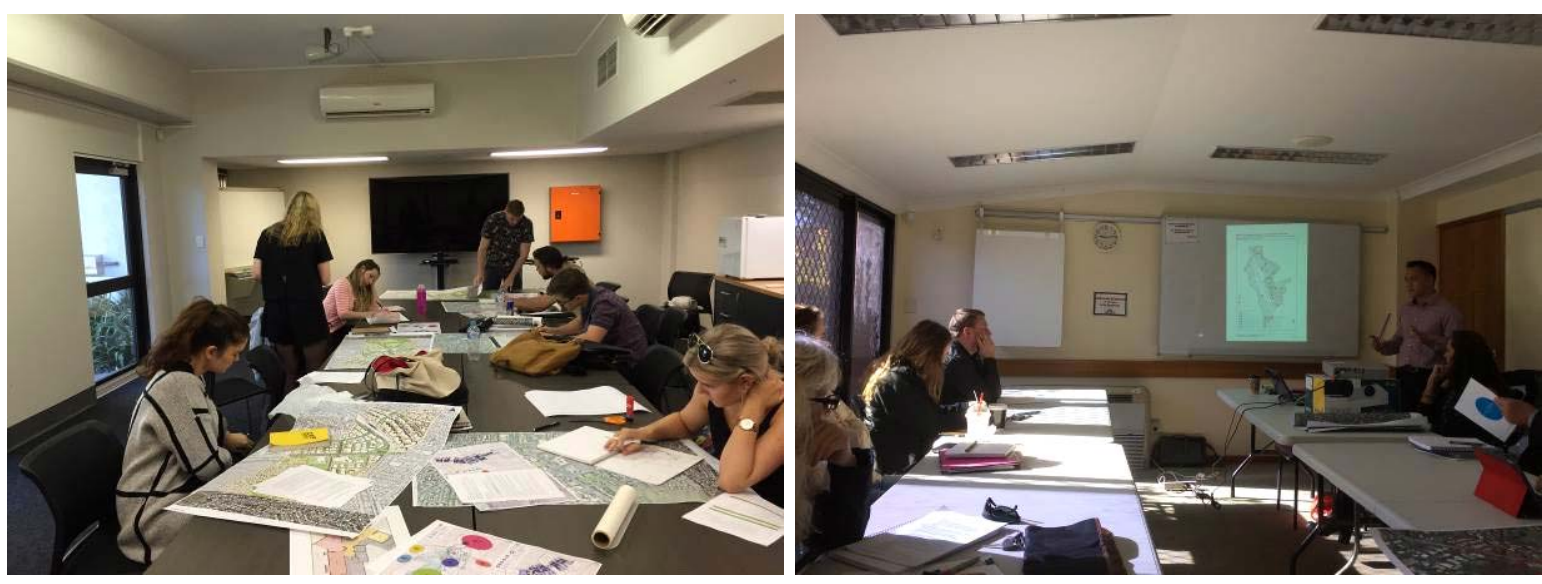

Figure 3 (left). Student developing their concepts during the 2016 charette.

Figure 4 (right). Johnny Pong from Logan City Council explaining the brief to students during the 2017 charette.

The format of the charrette has successfully provided students with a unique real-world learning experience and Council with a range of ideas and scenarios that have shown possibilities and potential development avenues for the localities investigated. In recognition of this positive experience, in 2016 LCC has included a student category in its Logan Urban Design Award, which was conferred to Ethan Fitzpatrick for his design proposition on Logan Central Civic and Community Precinct.

\section{To cite this article:}

Guaralda, M. (2017). Urban Coding in Logan. Teaching urban design with the support of local government. The Journal of Public Space, 2(2), I8I-I88. DOI: I0.5204/jps.v2i2. 10 I

This article has been accepted for publication in The Journal of Public Space. Please see the Editorial Policies under the 'About' section of the journal website for further information.

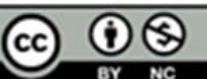

This work is licensed under a Creative Commons Attribution - Non Commercial 4.0 International License - https://creativecommons.org/licenses/by-nc/4.0/ 

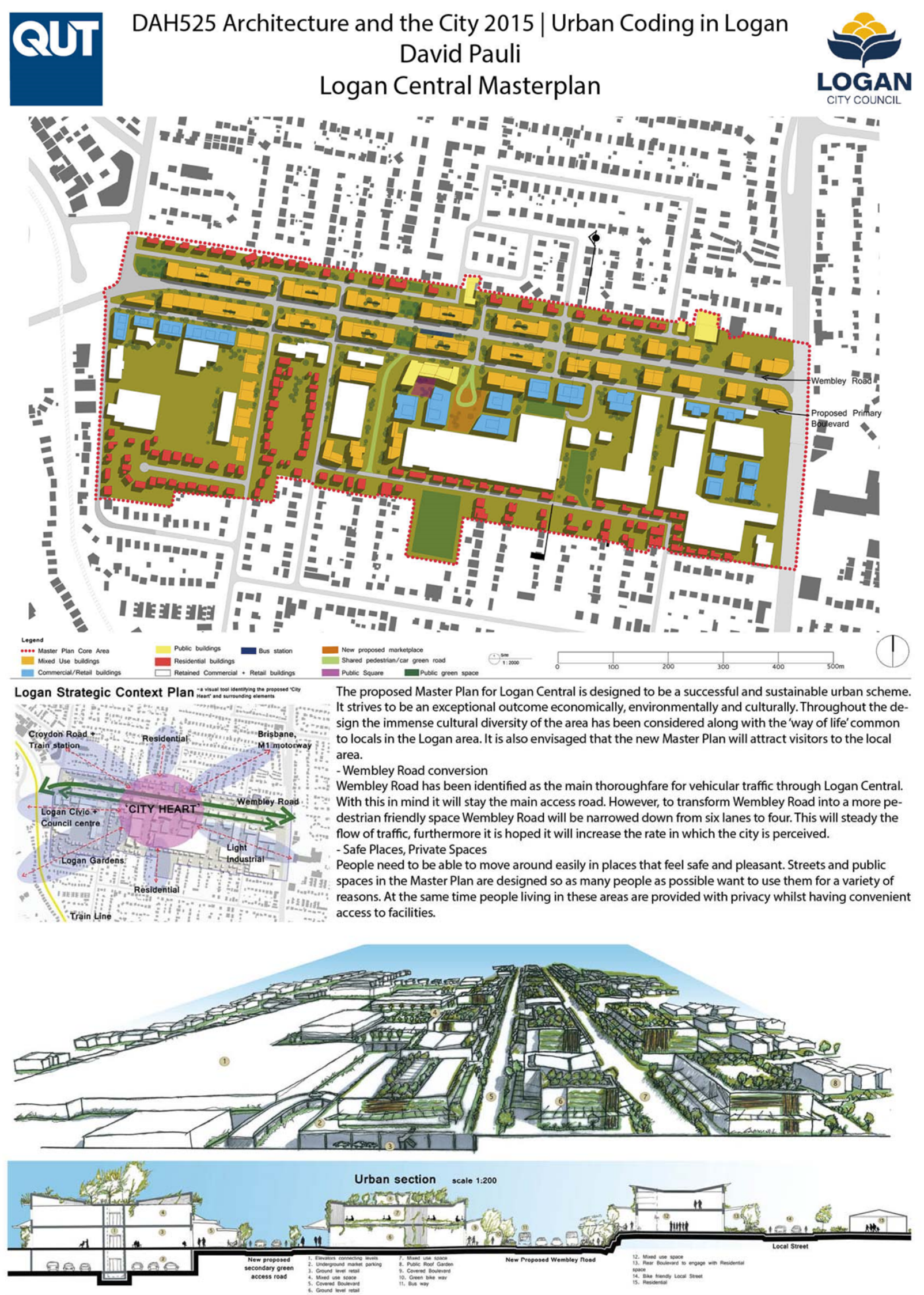


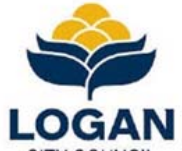

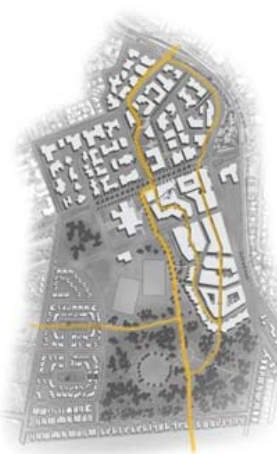

CONNECTIVITY

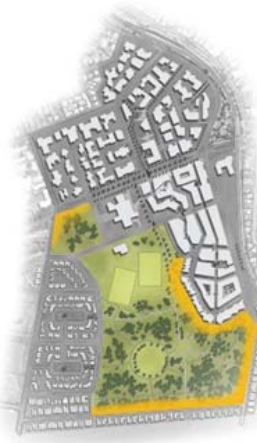

PARKEDGE ACTIVATION

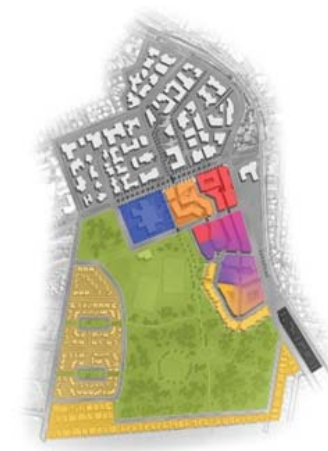

LAND USES

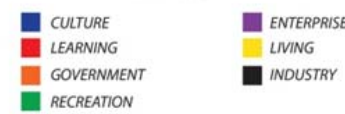

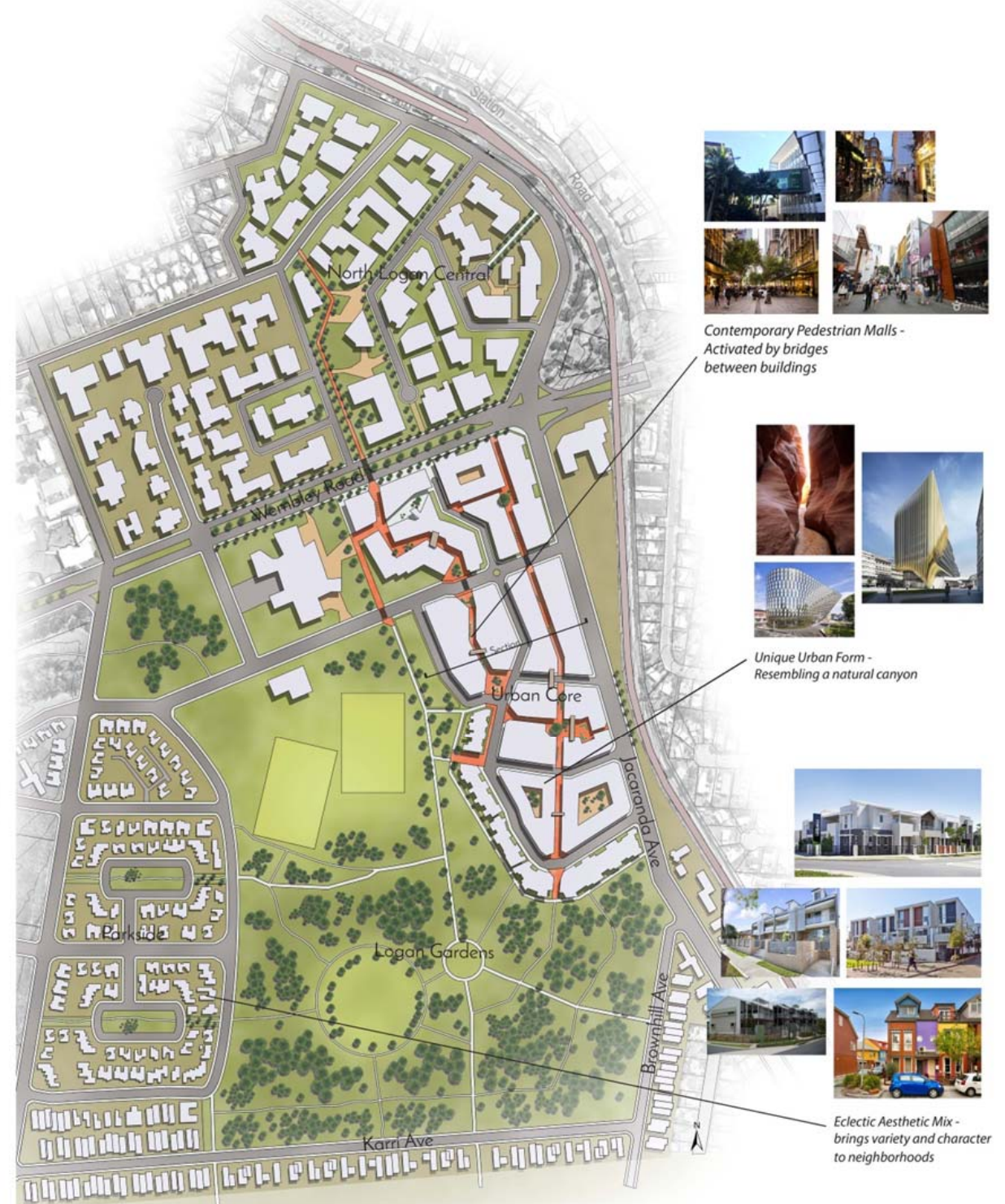

This master plan envisions a unique Genius Loci for Logan Central by creating an organic city grid, allowing for unique building shapes. Taking inspiration from the current council administrative building, the master plan calls for new buildings to be connected via pedestrian bridges, creating the opportunity for unique architecture, and architectural focal points. Thus achieving a greater versatility of buildings, and activating the urban core above street level. The Logan master plan area into the Logan Gardens Master Plan and beyond into residential areas

At the center of the Master Plan is the Logan Gardens which have been expanded to stretch from Brownhill Ave and Karri Ave in the south east to Wembly Road and Bardon Road in the northwest. This greatly improves street frontage and exposure of the parklands, with the added benefit of more open space.

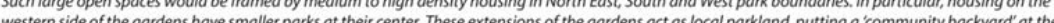

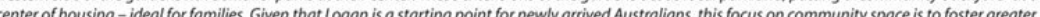
bonds between the various cultural groups and encourage sharing of knowledge

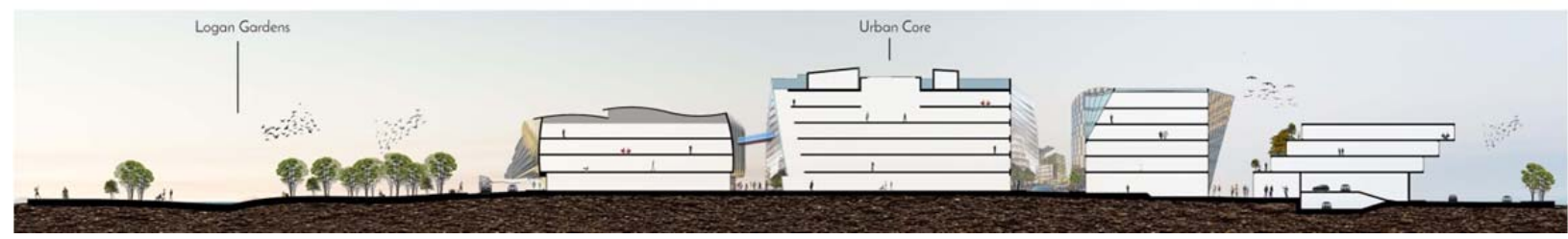

I84 | The Journal of Public Space, 2(2), 2017 | ISSN 2206-9658

(C) Queensland University of Technology 
The vision for Logan is a city that embraces the cultural diversity and facilitates the development of art, sport, economy, education and society. Districts for each of these objectives within an urban village will form the cultural heart of Logan.

The first step in accomplishing this will be inviting people to interact with the city, giving people the opportunity to walk and explore places rather than prioritising roads and cars.
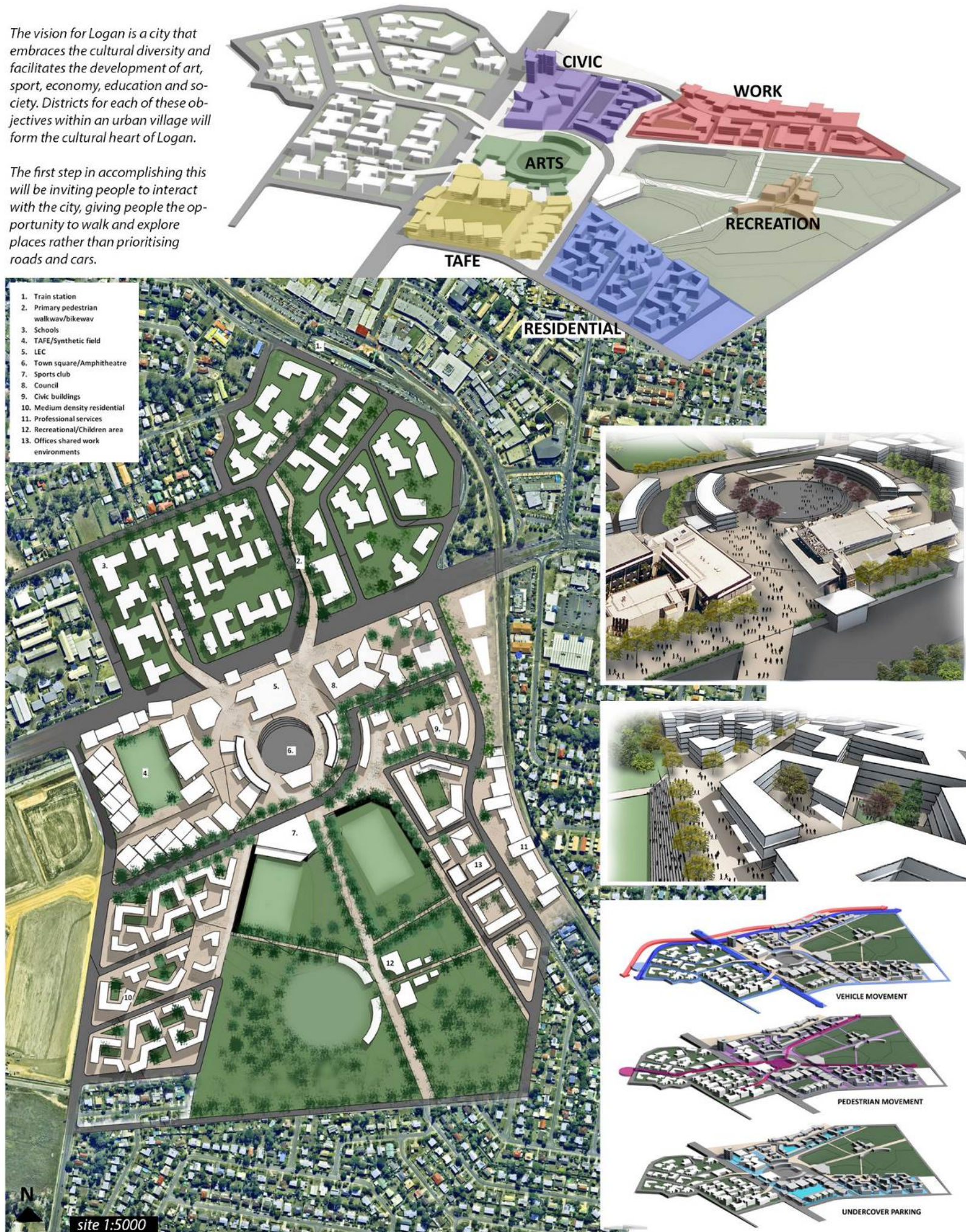

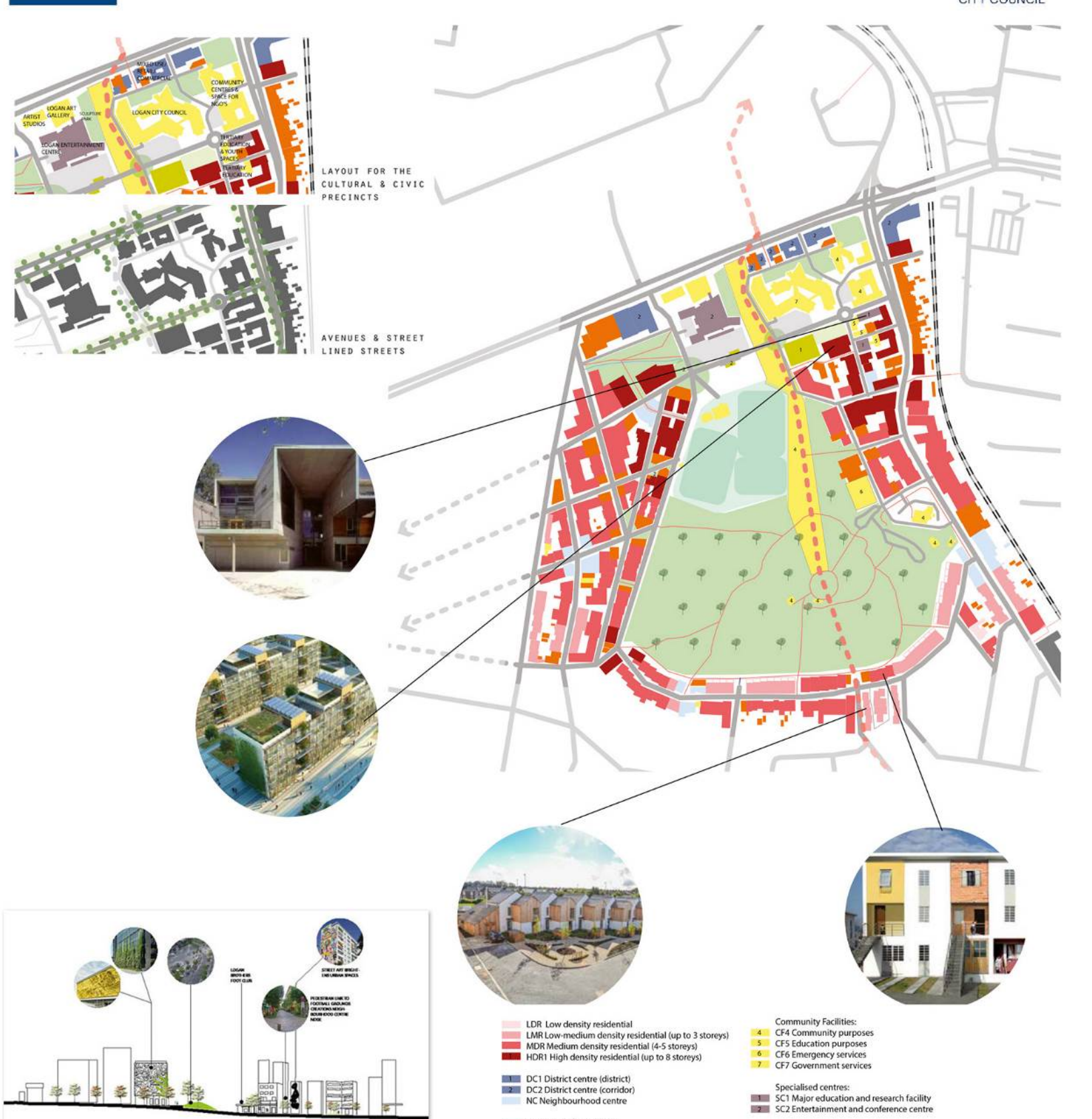

DC1 District centre (district)
DC2 District centre (corridor)
NC Neighbourhood centre

\section{SR Sport and recreation
OS1 Open space}

$\frac{1}{2}$ OS1 Open space
OS2 Open space (public square)

- Mu Mixed use

บRBAN SECHION

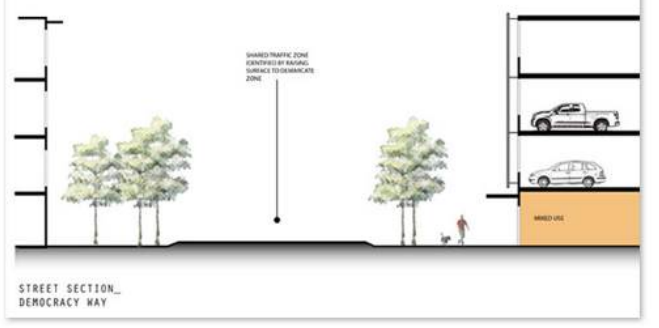

The vision for the urban masterplan of Logan Central is based on the specific desires and principles of Logan City Council and those important to the people, which reflect the unique social environment and together aim to create a vibrant, active city. Logan Central desires to be a new centre within the wider Logan area, that faces the challenges of integrating large numbers of refugees and immigrant, as well as high unemployment, crime and housing issues.

A significant number of these issues could potentially be mitigated with a better urban environment catering to the specific needs of a unique demographic. By treating Logan Central's social diversity as a key asset, this difference can be an important tool to unite people into strong, active communities many of which are already well established, but need the room to grow in size and influence. 


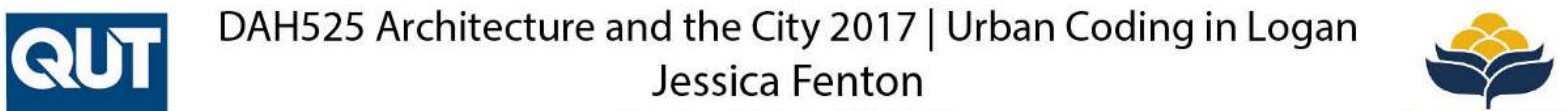 SpringWood $\mid C B D$ \\ LOGAN}
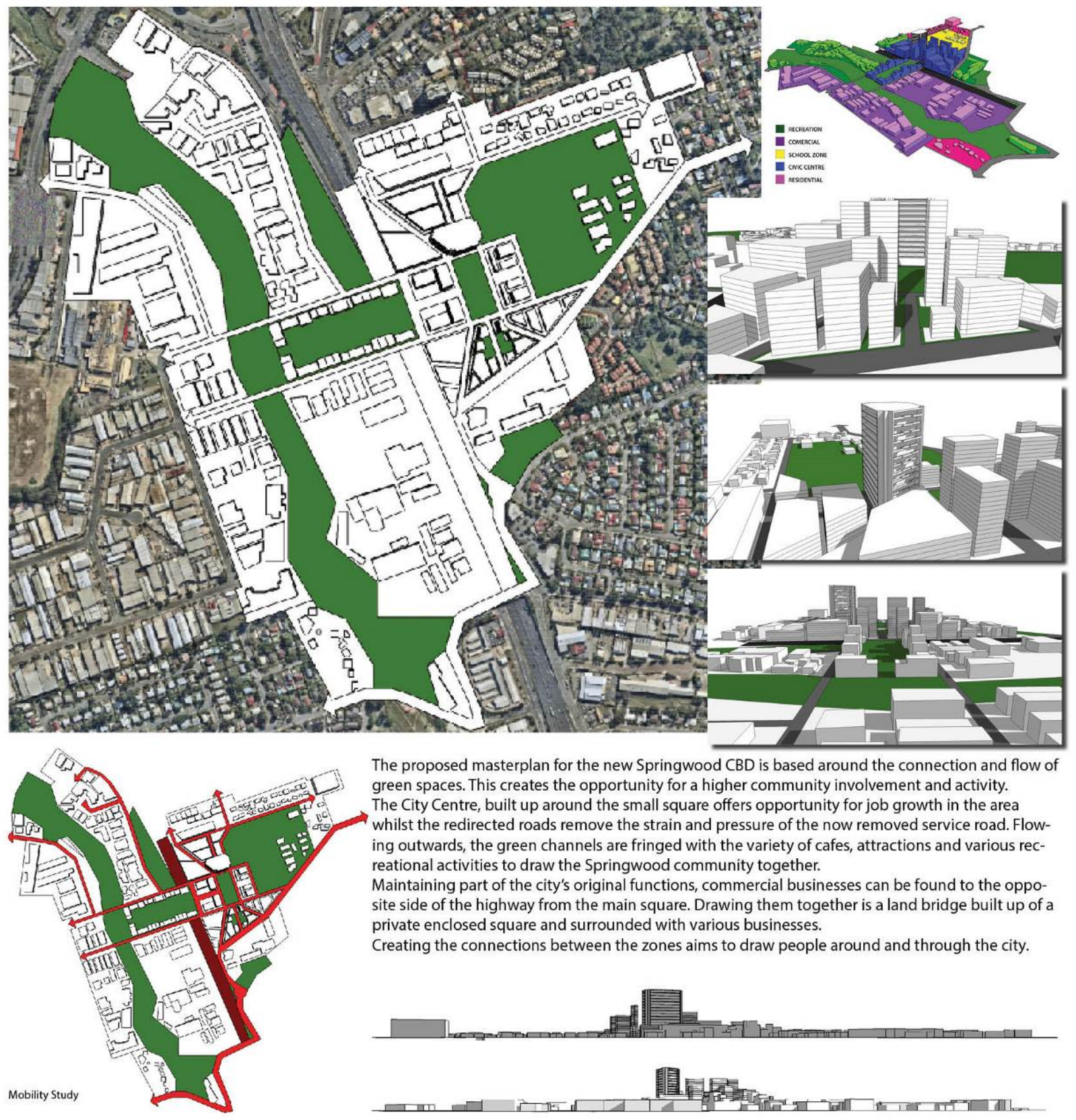

The proposed masterplan for the new Springwood CBD is based around the connection and flow of green spaces. This creates the opportunity for a higher community involvement and activity. The City Centre, built up around the small square offers opportunity for job growth in the area

whilst the redirected roads remove the strain and pressure of the now removed service road. Flowing outwards, the green channels are fringed with the variety of cafes, attractions and various recreational activities to draw the Springwood community together.

Maintaining part of the city's original functions, commercial businesses can be found to the opposite side of the highway from the main square. Drawing them together is a land bridge built up of a private enclosed square and surrounded with various businesses.

Creating the connections between the zones aims to draw people around and through the city.

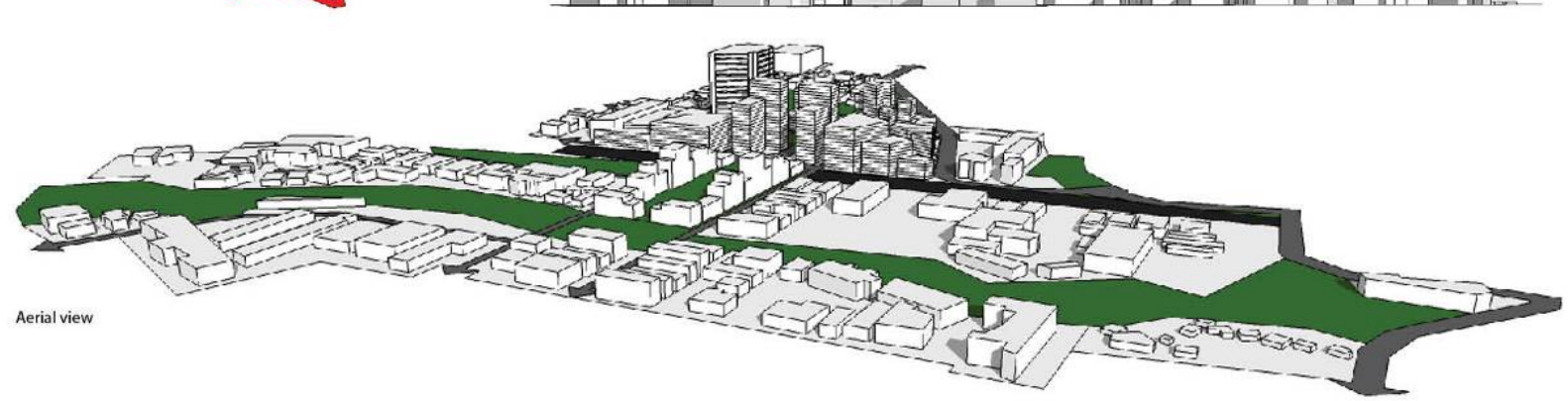


QU1 DAH525 Architecture and the City 2017 | Urban Coding in Logan
Kristofer Rohde-Estes
Springwood Central

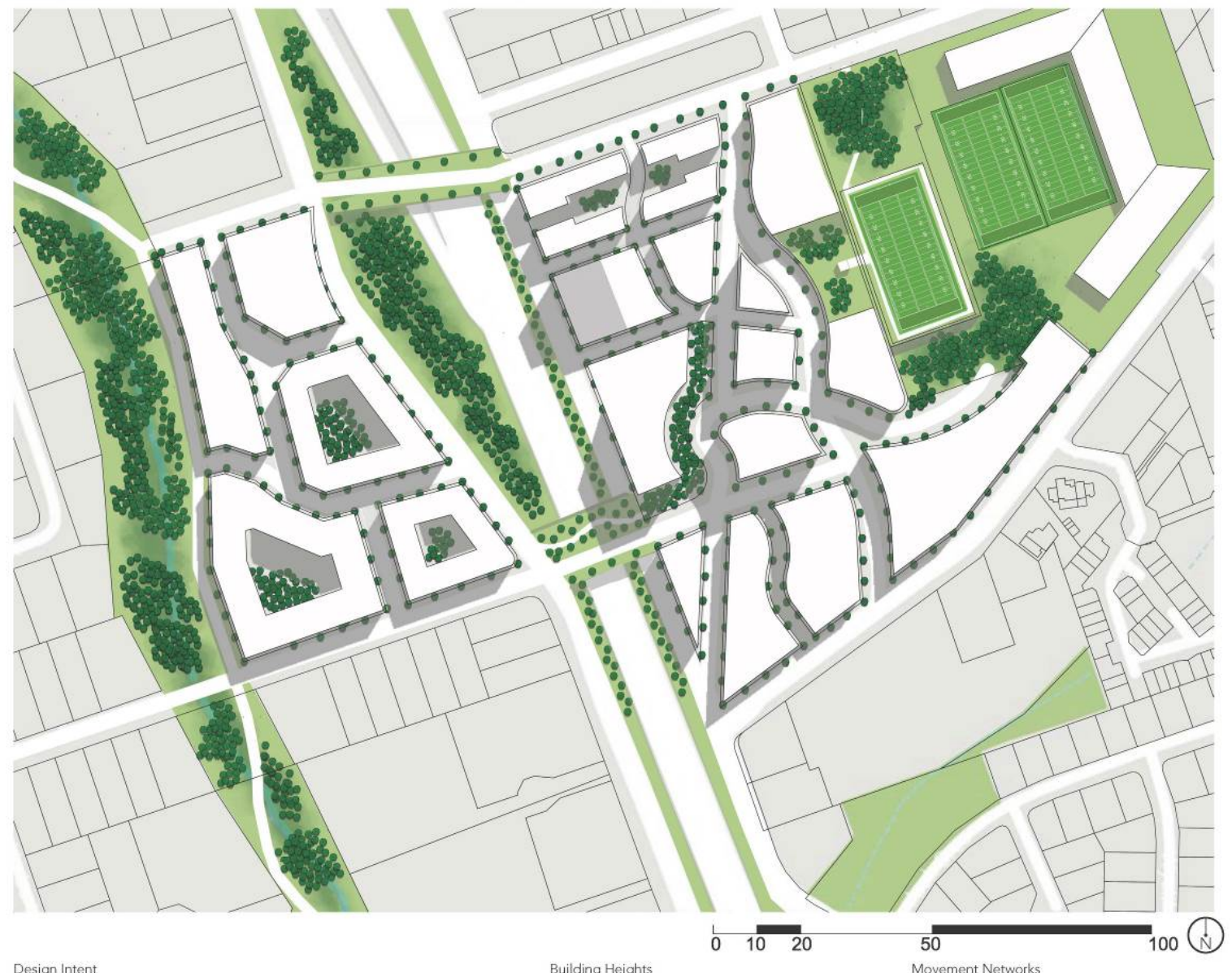

Design Intent

The overarching principles for the proposed Springwood central masterplan is to create green linkages and streetscape activation to

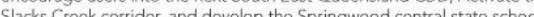
to incorperate prinary and seconday sho ling tose to the CBD. The green linkages connect the new commercial district to a Stacks Creek Corridor redevelopment that aims to engage users with their environment and to activate the creek frontage. Development will consist of mixed use residential/commercial zones and commercial only zones with vibrant streetscapes incorporating many roads into shared carriageways. Combining mix use residential/commercial buildings into the urban fabric of the CBD will allow for workers to utilise the walkability of the springwo

Indicative Streetscape

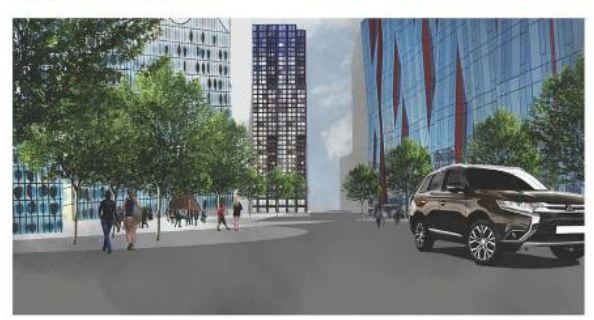

Building Heights

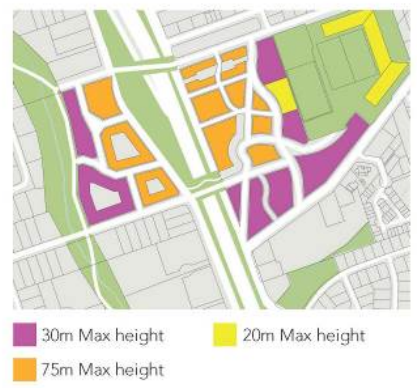

Morphology

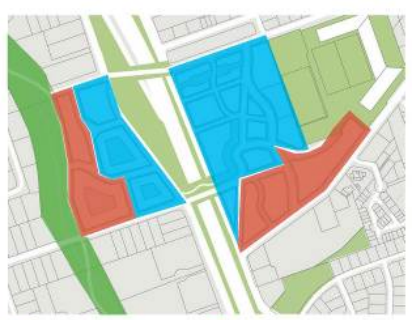

Slacks Creek Corridor $\quad$ Commercial

Mix Use

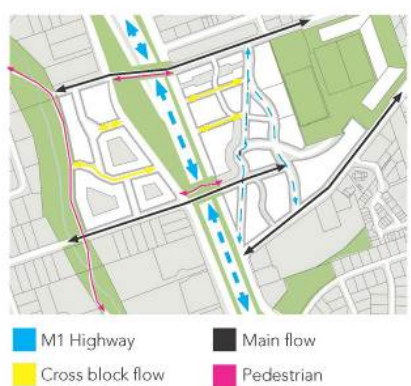

Green Linkages

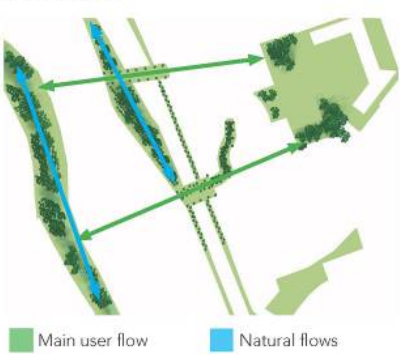

I 88 | The Journal of Public Space, 2(2), 2017 | ISSN 2206-9658

(c) Queensland University of Technology 